\title{
Summertime cooling of the shallow continental shelf
}

\author{
Melanie R. Fewings ${ }^{1,2}$ and Steven J. Lentz ${ }^{3}$ \\ Received 21 October 2010; revised 8 April 2011; accepted 21 April 2011; published 19 July 2011.
}

[1] In summer on the shallow New England continental shelf, near the coast the water temperature is much cooler than the observed surface heat flux suggests. Using depth-integrated heat budgets in 12 and $27 \mathrm{~m}$ water depth calculated from observed surface heat flux, water temperature, and velocity, we demonstrate that on time scales of weeks to months the water is persistently cooled due to a mean upwelling circulation. Because the mean wind is weak, that mean circulation is likely not wind driven; it is partly a tidal residual circulation. A feedback exists between the cross-shelf and surface heat fluxes: the two fluxes remain nearly in balance for months, so the water temperature is nearly constant in spite of strong surface heating (the heat budget is two-dimensional). A conceptual model explains the feedback mechanism: the short flushing time of the shallow shelf produces a near steady state heat balance, regardless of the exact form of the circulation, and the feedback is via the influence of surface heating on temperature stratification. Along-shelf heat flux divergence is apparently small compared to the surface and cross-shelf heat flux divergences on time scales of weeks to months. Heat transport due to Stokes drift from surface gravity waves is substantial, warms the shallow shelf in summer, and was previously ignored. In winter, the surface heat flux dominates and the observed water temperature is close to the temperature predicted from surface cooling (the heat budget is one-dimensional); weak winter stratification makes the cross-shelf heat flux small even during strong cross-shelf circulation.

Citation: Fewings, M. R., and S. J. Lentz (2011), Summertime cooling of the shallow continental shelf, J. Geophys. Res., 116, C07015, doi:10.1029/2010JC006744.

\section{Introduction}

[2] The continental shelf waters of the Middle Atlantic Bight (MAB) off the northeastern United States display a strong seasonal variation in temperature [Bigelow, 1933]. In winter the water temperature is near the freezing point, and in summer the near-surface temperature exceeds $20^{\circ} \mathrm{C}$ (Figure 1). Over the middle and outer shelf, the rise in water temperature from spring to summer is consistent with a local response to surface heating in both the northern [Lentz et al., 2003a, 2003b] and southern MAB [Flagg et al., 2002]. Over the shallowest part of the shelf (water depth less than $\sim 30 \mathrm{~m}$ ), however, the water does not warm as much as expected for a local response to surface heating (Figure 2). Apparently, advective transport of heat cools the shallowest part of the shelf in summer. In this paper, "shallow shelf" indicates the region of advective cooling suggested by Figure 2. This

\footnotetext{
${ }^{1}$ MIT/WHOI Joint Program in Oceanography/Applied Ocean Science and Engineering, Woods Hole, Massachusetts, USA.

${ }^{2}$ Now at Marine Science Institute, University of California, Santa Barbara, California, USA.

${ }^{3}$ Department of Physical Oceanography, Woods Hole Oceanographic Institution, Woods Hole, Massachusetts, USA.

Copyright 2011 by the American Geophysical Union. 0148-0227/11/2010JC006744
}

study focuses on the seasonal advective heat flux divergence (HFD), which controls the temperature of the shallow shelf waters on time scales of months.

[3] Cross-shelf advection of heat is an important cooling mechanism on the west coast of North America. The prevailing upwelling-favorable winds [e.g., Hickey, 1979] drive a mean coastal upwelling circulation that cools the shelf by transporting warm water offshore in the surface layer in spring [Dever and Lentz, 1994] and summer [Lentz, 1987]. In contrast, in the MAB the mean summer wind stress is an order of magnitude weaker than on the west coast [Saunders, 1977] and there is not a seasonally enhanced upwelling circulation [Lentz, 2008b]. Cross-shelf advection is not needed to close the heat balance on the middle and outer shelf in the MAB (previous paragraph), but we show that cross-shelf advection is important in the heat balance on the shallow part of the shelf.

[4] Persistent advective cooling in water depths less than $\sim 25 \mathrm{~m}$ has not previously been observed over the MAB shelf. Episodic upwelling events on time scales of days do lead to advective cooling of the shelf waters off New Jersey [Kohut et al., 2004] and North Carolina [Austin, 1999] and could produce mean cooling over a time period of weeks. Persistent advective cooling was inferred off Virginia by comparing the surface heat flux and observed heat content [Bignami and Hopkins, 2003] similarly to Figure 2. In a numerical modeling study of the summer 2002 heat budget 

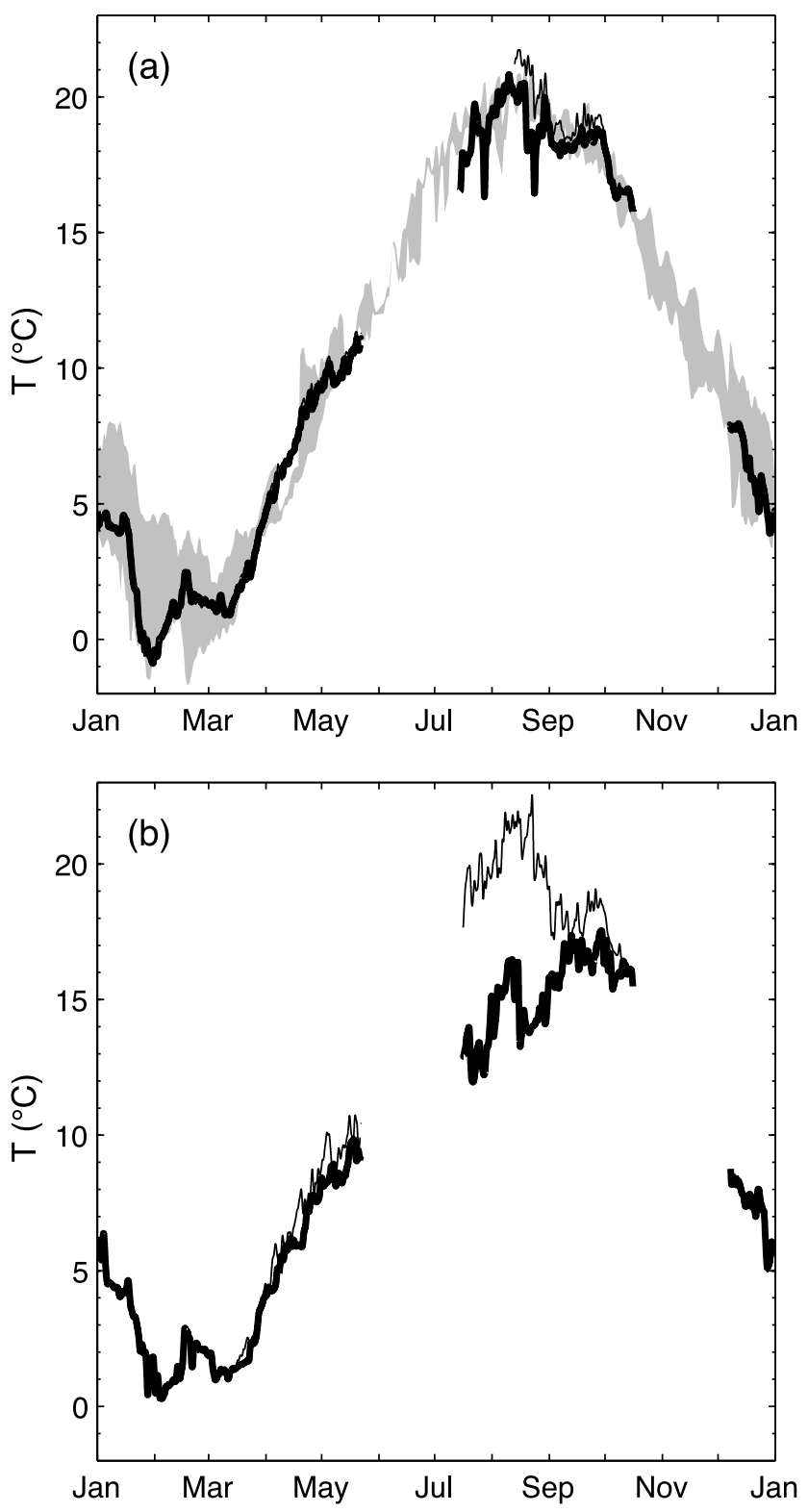

Figure 1. The $33 \mathrm{~h}$ low-pass-filtered temperature at (a) $12 \mathrm{~m}$ and (b) $27 \mathrm{~m}$ water depth at the Martha's Vineyard Coastal Observatory. Thick lines indicate near-bottom temperature; thin lines indicate near-surface temperature, from summer 2003 and winter 2004-2005. Grey shading indicates envelope of near-bottom temperature at the $12 \mathrm{~m}$ site from 2001 to 2007 , during all times other than those represented by the black lines; data are sparse in early summer.

in the northern MAB, the increase in water temperature on the shallow shelf was smaller than expected from surface heating alone, and an advective HFD cooled the inner shelf [Wilkin, 2006], also in agreement with Figure 2.

[5] We consider the three-dimensional heat balance of the shallow New England shelf (water depths 12 and $27 \mathrm{~m}$ ) on time scales of weeks to seasons. The cross-shelf, not alongshelf, HFD is the dominant cooling mechanism in 12 and $27 \mathrm{~m}$ water depth throughout the summer. There is a feedback between the surface and cross-shelf heat fluxes via the temperature stratification. Stokes drift substantially affects the cross shelf HFD by canceling part of the cooling heat flux carried by the Eulerian circulation. Most prior studies ignored Stokes drift and likely overestimated the cross-shelf heat flux as a result. In winter, the cross-shelf HFD warms the shallow shelf but is negligible compared to surface cooling and change in water temperature.

\section{Data}

[6] Water velocity was recorded throughout the water column with acoustic Doppler current profilers from 2001 to 2007 on the $12 \mathrm{~m}$ isobath at the Martha's Vineyard Coastal Observatory (MVCO), $1.5 \mathrm{~km}$ from shore (Figure 3, node), and from August to October 2003 and December 2004 to May 2005 on the $27 \mathrm{~m}$ isobath nearby (F). Water temperature was recorded (1) near bottom on the $12 \mathrm{~m}$ isobath from 2001 to 2007 (node), (2) throughout the water column on the 12 and $27 \mathrm{~m}$ isobaths during the 2003-2005 deploy-

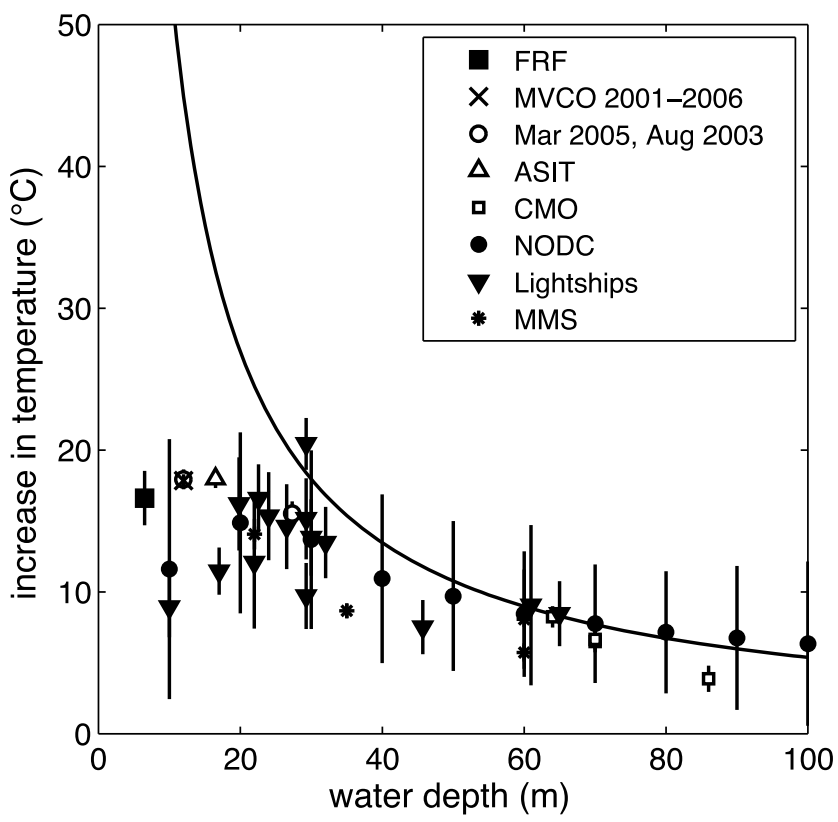

Figure 2. Comparison of observed changes in water temperature over the summer with prediction based on surface heat flux, for various sites in the MAB. Solid line shows predicted increase in depth-average temperature due to the mean net surface heat flux of $140 \mathrm{~W} \mathrm{~m}^{-2}$ observed at MVCO during 1 March to 31 August, assuming no advection of heat (section 3.1). Symbols show observed change in 10 day average temperature for same time period. Vertical bars show tone standard deviation. For description of U.S. Army Corps of Engineers Field Research Facility daily data, see http://www.frf.usace.army.mil; Coastal Mixing and Optics data and National Ocean Data Center archived shipboard data, see Lentz et al. [2003b]; lightship temperature measurements, see http://dlaweb.whoi.edu/DIG_RES/lightship_data. html; and Minerals Management Service Hatteras Study, see Berger et al. [1994]. 

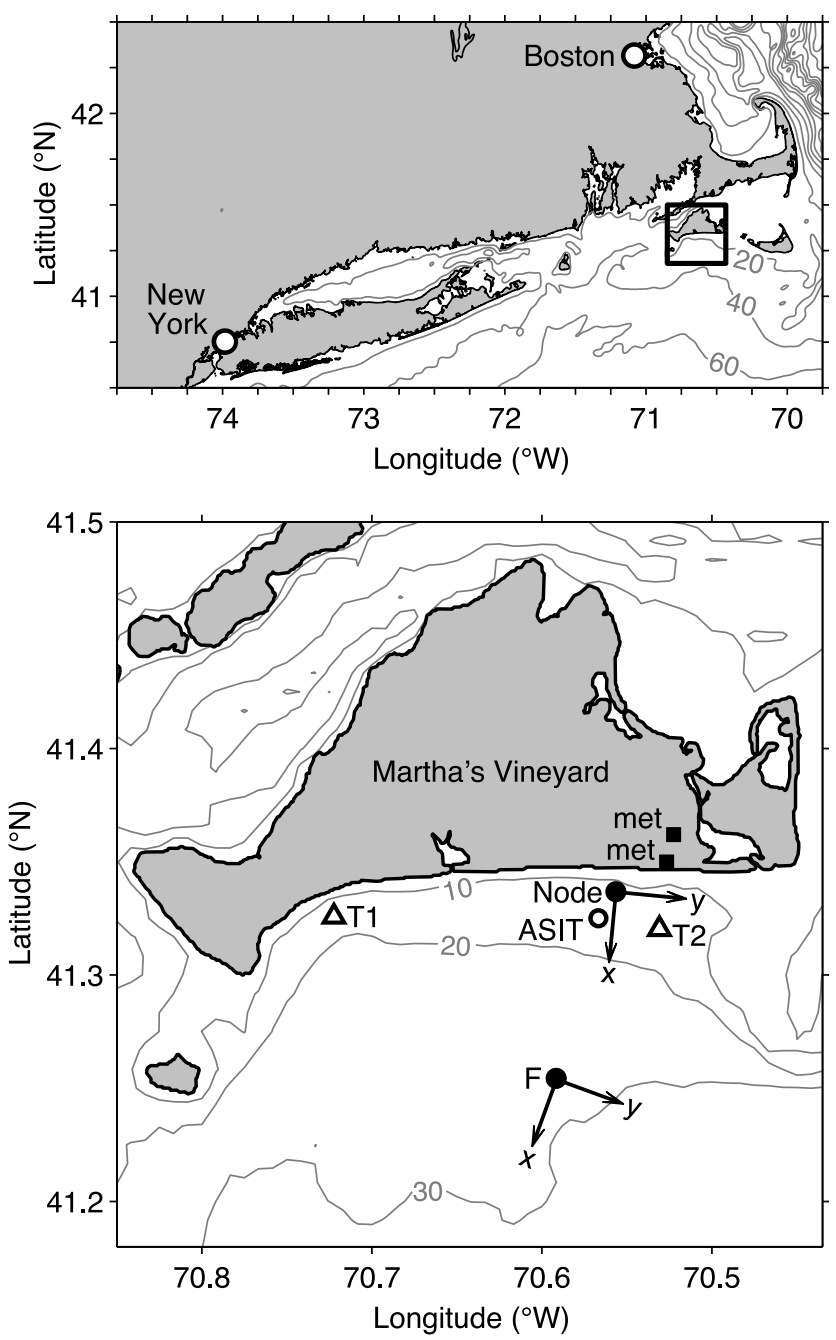

Figure 3. (top) Location of study area (box). Isobaths are labeled in meters. (bottom) Detailed map of study area with principal axis coordinate systems [Lentz et al., 2008]. Solid circles indicate moorings on the 12 and $27 \mathrm{~m}$ isobaths (node and F, respectively), deployed during summer-fall 2003 and fall-winter 2004-2005. Triangles indicate moorings $\mathrm{T} 1$ and T2, deployed during summer-fall 2003 only. Open circle indicates MVCO air-sea interaction tower (ASIT). Squares indicate MVCO meteorological masts.

ments (node, F), and (3) throughout the water column on the $15 \mathrm{~m}$ isobath during the 2003 deployment (T1, T2).

[7] Meteorological data from MVCO were used to calculate net surface heat flux with Fairall et al.'s [2003] bulk algorithms (Figure 4). The dominant wave characteristics were provided by MVCO as described at http://www.whoi. edu/mvco. All time series are $20 \mathrm{~min}$ averages of data recorded at higher frequencies. Tidal contributions to the velocity and temperature signals were determined with T_TIDE [Pawlowicz et al., 2002]. In section 4.4, "highfrequency" variations were removed by low-pass filtering with a half-amplitude cutoff of $(33 \mathrm{~h})^{-1}$ [Limeburner et al., 1985]. At each mooring location, the water velocity $\boldsymbol{u}=$ $(u, v)$ and wind stress $\tau_{s}=\left(\tau_{s}^{x}, \tau_{s}^{y}\right)$ are rotated into a local coordinate system with $x$ positive offshore and $y$ positive along-shelf eastward (Figure 3), defined by the principal axes of the subtidal depth-averaged flow when waves are small [Lentz et al., 2008]. More details about the instruments, observations, and data processing are provided by Fewings et al. [2008] and Fewings [2007].

\section{Methods}

\subsection{The 1-D Heat Budget: No Advection}

[8] If the temperature balance is one-dimensional (no dependence on $x$ or $y$ ) and there is no heat flux into the seafloor, the change in depth-average water temperature $\langle T\rangle$ over time at a water depth $h$ is determined solely by the net surface heat flux $Q_{s}$ :

$$
\langle T\rangle(t)-\langle T\rangle(t=0)=\frac{1}{\rho_{0} c_{p} h} \int_{0}^{t} Q_{s}\left(t^{\prime}\right) d t^{\prime}
$$

where $\rho_{0}=1025 \mathrm{~kg} \mathrm{~m}^{-3}$ and $c_{p}=4010 \mathrm{~J} \mathrm{~kg}^{-1}{ }^{\circ} \mathrm{C}^{-1}$ are the reference density and specific heat capacity of seawater, respectively [e.g., Pedlosky, 1987]. It is reasonable to neglect heat flux into the seafloor because only $7 \%$ of the net surface heat flux penetrates to the bottom at the $12 \mathrm{~m}$ site, based on observed August heat flux and the formula by Paulson and Simpson [1977] for absorption of radiation with the coastal water Type III coefficients from Jerlov [1968] (for details, see Fewings [2007, section 4.3.5]). Equation (1) with $Q_{s}=140 \mathrm{~W} \mathrm{~m}^{-2}$ produced the predicted curve in Figure 2.

\subsection{The 3-D Heat Budget for a Wedge With Waves}

[9] The observed area-average temperature of the wedge of water onshore of a mooring at $x=L$ is $\langle\langle T\rangle\rangle$. The time rate of change of $\langle\langle T\rangle\rangle$ due to surface, cross-shelf, and along-shelf heat fluxes is

$$
\langle\langle T\rangle\rangle_{t}=\frac{1}{\rho_{0} c_{p} A}\left(H^{s}+H^{x s}+H^{a s}\right)
$$

where the subscript $t$ represents a time derivative, $A$ is the area of the wedge, and the $H$ variables are heat fluxes into the wedge, per unit along-shelf length (units $\mathrm{W} \mathrm{m}^{-1}$ ). The available observations are sufficient to quantify all the terms in (2) except $H^{a s}$. The surface heat flux is

$$
H^{s}=\int_{0}^{L} Q_{s} d x
$$

The cross-shelf HFD is

$$
H^{x s}=-\left.\rho_{0} c_{p} \int_{-h}^{0}\left(u+u_{s t}\right) \widetilde{T} d z\right|_{x=L}
$$

where $h(x)$ is water depth, $u_{s t}$ is the $x$ component of the Stokes drift velocity and $\widetilde{T} \equiv T-\langle T\rangle$ is the depth-varying 

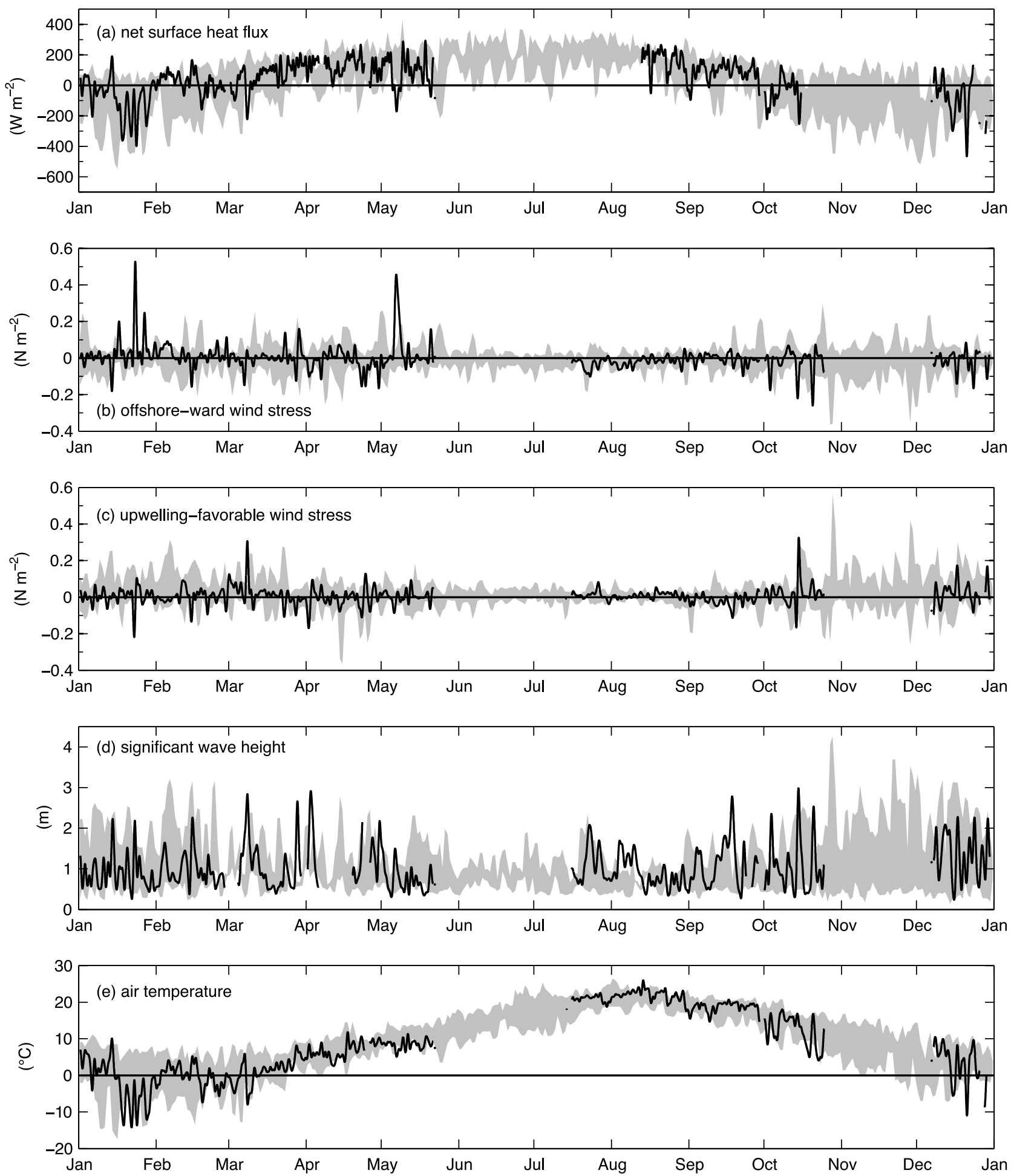

Figure 4. The $33 \mathrm{~h}$ low-pass-filtered net surface heat flux $Q_{s}$, cross-shelf and along-shelf wind stress, wave height, and air temperature. Black line indicates summer 2003 and winter/spring 2004-2005 deployments. Grey shading indicates envelope of other measurements at MVCO (2001-2007). 

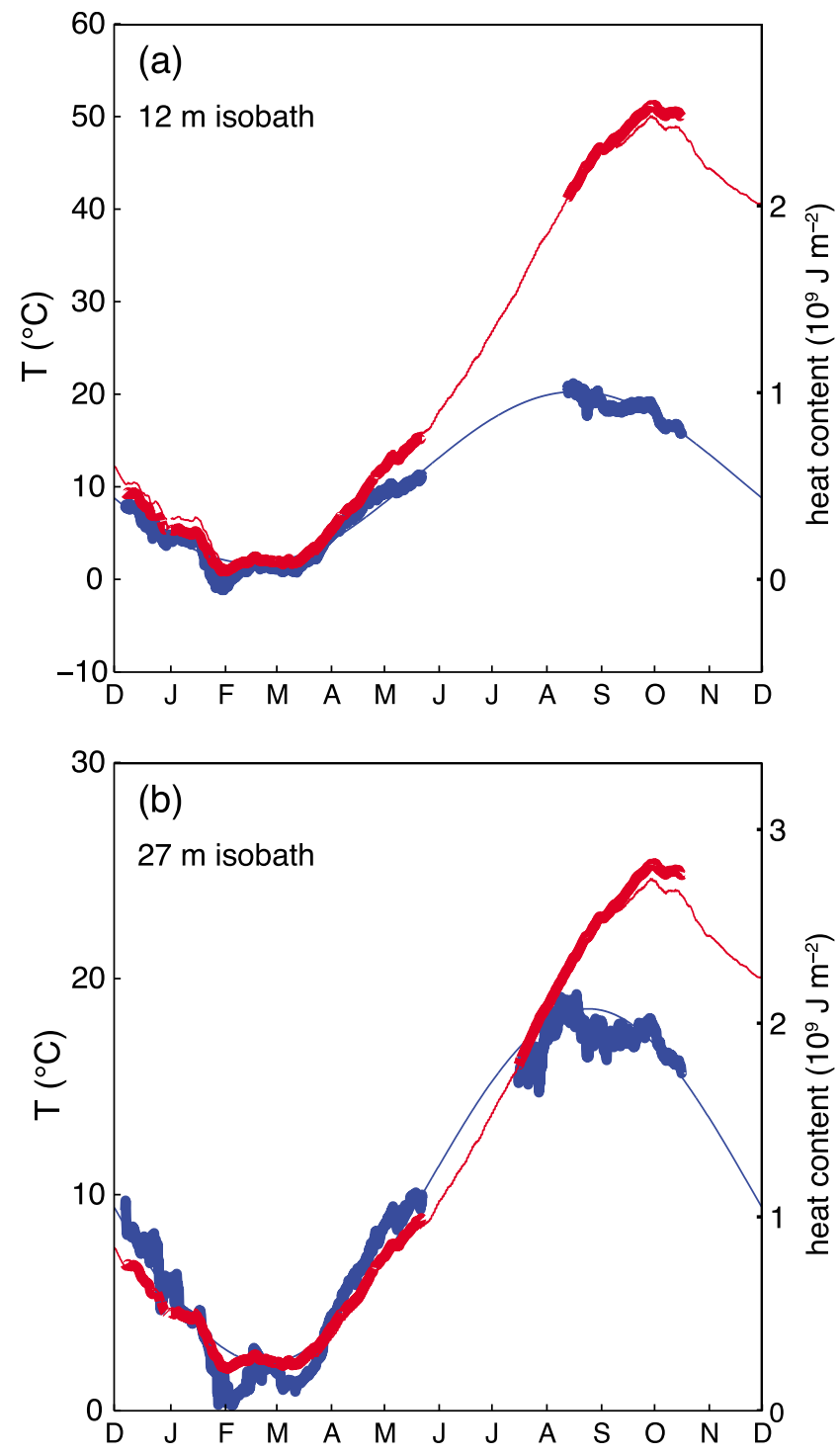

Figure 5. Annual cycle of depth-average temperature on the (a) $12 \mathrm{~m}$ and (b) $27 \mathrm{~m}$ isobaths. Thick blue curve shows observed $\langle T\rangle$. Thin blue curve shows best fit sinusoidal annual cycle of $\langle T\rangle$. Thick red line shows depth-average temperature predicted from surface heat flux via equation (1). Thin red curve shows predicted annual cycle from observed meteorology and best fit sinusoidal annual cycle of nearsurface temperature (not shown). Equivalent water column heat content per unit horizontal area is shown on the right axis, relative to heat content of a water column at $0^{\circ} \mathrm{C}$. The red curves have been aligned vertically as described by Fewings [2007, Appendix C.1] to show times when the slopes of the red and blue curves agree, indicating a one-dimensional heat budget.

part of the temperature profile. The along-shelf HFD has two parts:

$$
H^{a s}=H_{a d v}^{a s}+H_{1}^{a s}
$$

The term $H_{1}^{a s}$ represents terms that cannot be estimated from these observations, terms due to along-shelf variations in wave properties or water velocity. The term $H_{a d v}^{a s}$ is due to advection of along-shelf temperature gradients:

$$
H_{a d v}^{a s}=-\rho_{0} c_{p} \int_{0}^{L} \int_{-h}^{0} v \frac{\partial}{\partial y}\left(T-\left.\langle T\rangle\right|_{x=L}\right) d z d x
$$

We quantified $H_{a d v}^{a s}$ as well as possible from the available observations; calculation of $H_{a d v}^{a s}$ is described in Appendix A. Calculation of the other heat budget terms and a derivation of the above equations are in Appendices $\mathrm{C}$ and $\mathrm{D}$ of Fewings [2007].

\section{Results}

\subsection{Annual Cycles of Water Temperature and Surface Heat Flux}

[10] Water temperature at MVCO has a pronounced annual cycle, ranging from the freezing point in winter to over $20^{\circ} \mathrm{C}$ in summer (Figure 1). The top-to-bottom temperature difference also has a strong seasonal cycle and ranges from $3^{\circ} \mathrm{C}$ in August to $-0.3^{\circ} \mathrm{C}$ in winter (see Fewings [2007] for details). Generally, the near-surface water is warmer near shore in summer and colder nearshore in winter. These results are consistent with previous observations on the MAB shelf [Bigelow, 1933].

[11] The net surface heat flux on average warms the ocean on time scales of days and longer from March through September, and cools the ocean from October through February (Figure 4a). The pronounced seasonal cycle in net surface heat flux, with maximum heating in June and July, is mainly due to the seasonal cycle of solar radiation. The solar, longwave, sensible, and latent contributions to the net heat flux are described by Fewings [2007] and are consistent with previous studies of surface heat flux in the MAB [Joyce, 1987].

\subsection{Heat Budget Without Advection Does Not Close}

[12] The time-integrated heat budgets calculated from equation (1) indicate the water temperature in summer is colder than predicted from accumulated surface heating (Figure 5), as expected from Figure 2. The departure of the heat balance from 1-D, indicated by a difference in slope between the red and blue curves, begins earlier in shallower water: in April at the $12 \mathrm{~m}$ site but in August at the $27 \mathrm{~m}$ site.

[13] The observed water temperature is roughly constant at both sites during August and September (Figure 5), but not due to thermal equilibrium between the ocean and atmosphere. If the ocean and atmosphere were in thermal equilibrium the net surface heat flux would be zero, but it remains positive (Figure $4 \mathrm{a}$ ). The sea surface temperature required for radiative equilibrium, based on the mean observed meteorology from August, is $25-26^{\circ} \mathrm{C}$ but the observed nearsurface temperature does not exceed $22^{\circ} \mathrm{C}$.

[14] In December-March at the $12 \mathrm{~m}$ site, the water cools as much as expected from the accumulated surface cooling (red and blue lines have the same slope in Figure 5), indicating advective warming of the shallow shelf in winter is negligible on time scales of weeks to months. At the $27 \mathrm{~m}$ site 

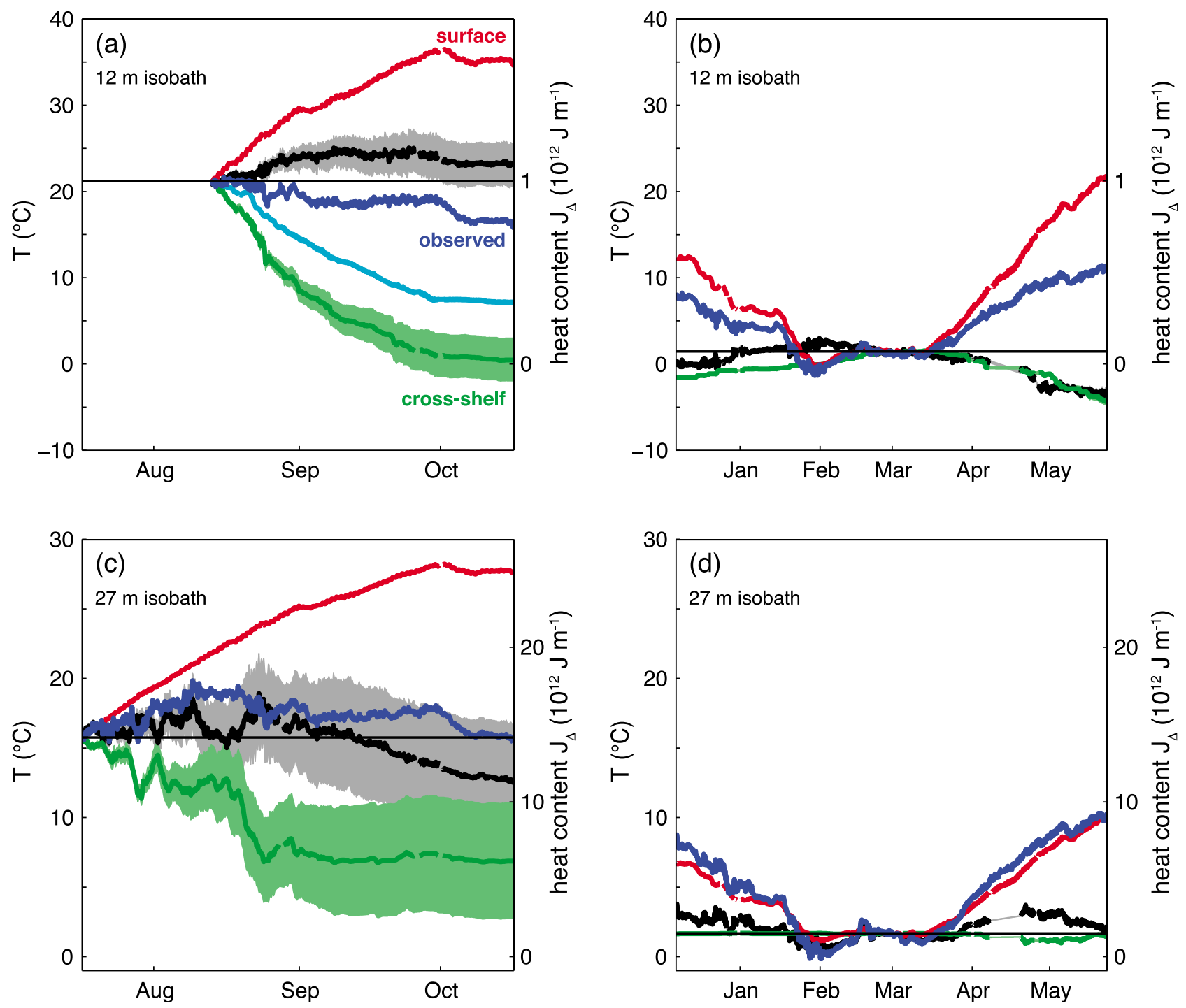

Figure 6. Time-integrated heat budget for a triangular wedge onshore of the (a and c) $12 \mathrm{~m}$ or (b and d) $27 \mathrm{~m}$ isobath (as in Figure 7), expressed as accumulated change in heat content per unit along-shelf length, in (left) summer and (right) winter. The equivalent temperature $\langle\langle T\rangle\rangle=J_{\Delta} / \rho_{0} c_{p} A$ is on the left axis. Blue curve shows observed heat content $J_{\Delta}$; reference "zero" on heat content axis is arbitrary. Red curve shows predicted heat content $J^{s}$ due to observed surface heat flux $H^{s} ; J^{s}$ is the time integral of $H^{s}$. Green curve shows predicted heat content $J^{x s}$ due to cross-shelf heat flux $H^{x s}$, including waves. Black curve shows residual, $J_{\Delta}-J^{x s}-J^{s}$. Light blue curve in Figure $6 \mathrm{a}$ is due to the estimated part of the along-shelf heat flux, $H_{a d v}^{a s}$. The shaded area around each curve shows the range produced by rotating the coordinate system $\pm 5^{\circ}$. Because integration constants for the time integrals of $H^{s}$ and $H^{x s}$ are unknown, the surface (red) and cross-shelf (green) heat flux curves are aligned vertically with the blue observed temperature at the beginning of the deployment for 2003 and on March 1 for 2004-2005.

the situation is similar except in February and March when the water twice cools and then heats more rapidly than can be explained by the surface heat flux. Advective transport of heat seems to be important at the $27 \mathrm{~m}$ site during those midwinter events, which each last a couple of weeks.

\subsection{Heat Budget With Advection}

[15] The 1-D heat budget above and Figure 2 both imply advective HFD cools the shallow shelf on time scales of weeks to months in summer. To determine whether the observed advective HFD accounts for the observed cooling, we consider a 3-D budget: the time integral of equation (2). In summer, the cross-shelf HFD alone (Figures 6a and 6c, green curve) is strikingly similar to the HFD needed to close the budget: after accounting for surface and cross-shelf heat fluxes, the residual (black) is small compared to the other terms. This indicates the summer heat budget at both sites is nearly two-dimensional, with surface heating $H^{s}$ and crossshelf HFD $H^{x s}$ roughly balancing each other (Figure 7a). The accumulated heat due to $H^{s}$ and the heat loss due to $H^{x s}$ are each 5-9 times as large as the change in local heat content (blue) from August to the beginning of October, when the 


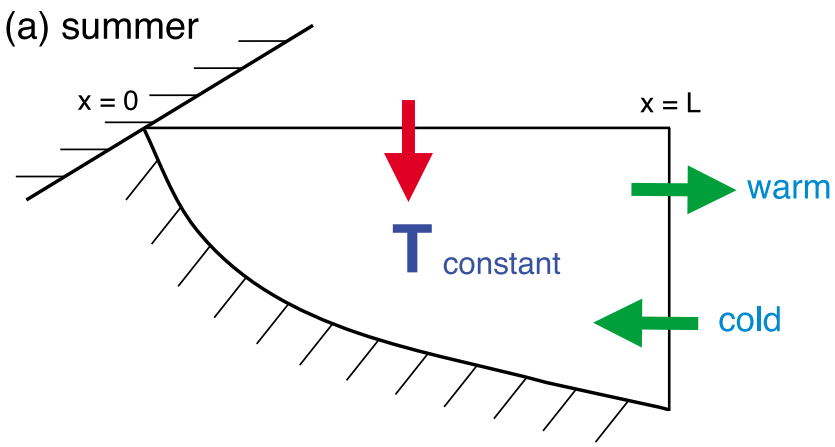

(b) winter

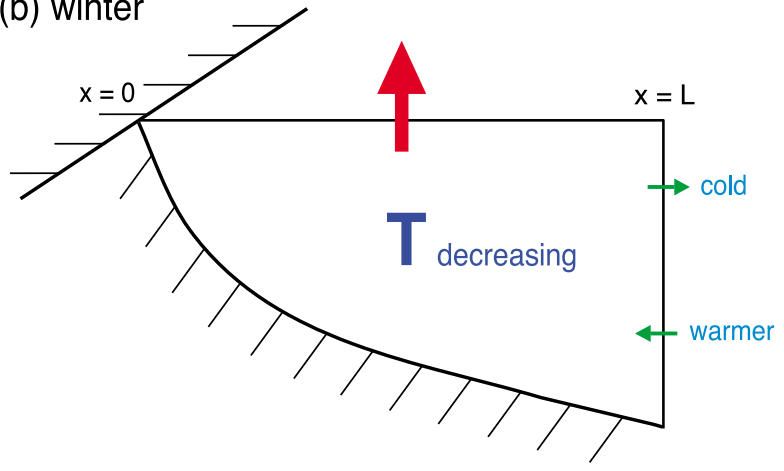

Figure 7. Cartoons of heat balance on time scales of weeks to months. (a) Summer; the net surface heat flux (red arrow) heats the shallow shelf water. The cross-shelf heat flux (green arrows) cools the shallow shelf and approximately cancels the surface heating, so the water temperature (blue $\mathrm{T}$ ) remains nearly constant. (b) Winter; the net surface heat flux (red arrow) cools the shallow shelf water. The cross-shelf heat flux (green arrows) warms the shallow shelf but is small in comparison to the surface heat flux, so the water temperature (blue T) decreases.

seasonal breakdown in temperature stratification occurs (Figures 6a and 6c). The cross-shelf heat flux adjusts to oppose the surface heat flux: the green and red curves in Figures $6 \mathrm{a}$ and $6 \mathrm{c}$ are almost mirror images, suggesting a feedback between the two fluxes.

[16] The along-shelf heat flux divergence term $H_{a d v}^{a s}$ is excluded from the budget because it is crudely estimated (Appendix A) and is only part of the total along-shelf HFD. The part of the along-shelf HFD that we cannot estimate likely cancels much of the part we can estimate, however, since the residual in the budget without including alongshelf HFD is small. The approximate balance between surface heating and cross-shelf advective cooling (Figures 6a and $6 \mathrm{c}$ ) implies the total along-shelf HFD is a relatively small term in the heat budget. The part of the along-shelf HFD we can estimate from the observations $\left(H_{a d v}^{a s}\right.$, Figure 6a light blue curve) is smaller than the cross-shelf heat flux but not negligible. Since the budget nearly closes without including $H_{a d v}^{a s}$, if our estimate of $H_{a d v}^{a s}$ is accurate, then the part of the along-shelf HFD that we cannot estimate $\left(H_{1}^{a s}\right.$ due to divergence of the along-shelf flow) should approximately cancel $H_{a d v}^{a s}$.

[17] In winter (December-March), the 3-D heat budget is consistent to first order with the 1-D budget in section 4.2
(Figures 6b, 6d, and 7b): the cross-shelf heat flux (green) and residual (black) are small compared to the other terms. At the shallower site, the cross-shelf heat flux actually warms the local waters. The cross-shelf HFDs at both sites in winter are small compared to the surface heat flux in spite of strong wind stress and wave forcing that do drive crossshelf circulation [Fewings et al., 2008; Lentz et al., 2008]. The cross-shelf HFDs are small in winter because the vertical temperature stratification over the shallow shelf is small, even though the cross-shelf circulation is not small.

[18] In December-January at the shallower site, there is a disagreement between the 1-D and 3-D budgets. The 1-D budget indicates a balance between the observed decrease in water temperature and the surface cooling (Figure 5a), but the 3-D budget indicates the observed decrease in water temperature is less than expected from the surface cooling (Figure 6b). The disagreement is likely because in the 3-D area budget the estimated water temperature can be inaccurate if the horizontal temperature gradient onshore of the $12 \mathrm{~m}$ site is large. When the budget is 1-D according to Figure 5a, indicating the advective HFD must be small, the 1-D heat budget should be more reliable than the $3-\mathrm{D}$ budget.

\subsection{Time Scales Contributing to Seasonal Cross-Shelf Heat Transport}

[19] The cross-shelf heat flux is important in summer, but it is unclear what processes drive that HFD. As a start toward characterizing the dominant processes, we consider what time scales of variation in circulation and temperature stratification contribute to the HFD. We decompose the cross-shelf HFD into three parts: due to (1) the time-mean circulation and temperature profile over each deployment, (2) the synoptic (time scale $>33 \mathrm{~h}$ ) fluctuations in the circulation and temperature profiles, and (3) the "high-frequency" (time scale $<33 \mathrm{~h}$ ) fluctuations in the circulation and temperature, each of which, if the fluctuations are correlated, could lead to a time-mean cross-shelf heat flux.

[20] The time-mean circulations $u$ and $u+u_{s t}$ at both sites in both seasons are more offshore near the surface than lower in the water column (Figures $8 b, 8 d, 8 g$, and $8 \mathrm{i}$ ). In summer, that circulation combines with a temperature profile that has warmer water near the surface (Figures $8 \mathrm{e}$ and $8 \mathrm{j}$ ) to yield a cross-shelf heat flux that cools the shallow shelf. In winter, the temperature at the $12 \mathrm{~m}$ site is slightly colder at the surface than the bottom so the same upwelling circulation actually warms the shallow shelf (see Fewings [2007, Figure 4-9 and section 4.4.3] for details).

[21] At each site, the mean flow accounts for $\sim 50-60 \%$ of the total cross-shelf heat flux during summer (not shown; see Fewings [2007, Figure 4-14] for details). The remainder of the cross-shelf heat flux at the $12 \mathrm{~m}(27 \mathrm{~m})$ site is mainly due to correlated velocity and temperature fluctuations with time scales shorter (longer) than $33 \mathrm{~h}$.

\subsection{Forcing Mechanisms for Cross-Shelf Heat Flux}

[22] The time-mean cross-shelf heat flux at the $12 \mathrm{~m}$ site in summer is likely not wind driven. The mean along-shelf wind stress during the 2003 deployment was not significantly different from zero, including during August when the crossshelf heat flux was strongest. In any case, the along-shelf wind is less effective than the cross-shelf wind at driving cross-shelf circulation at the $12 \mathrm{~m}$ site [Fewings et al., 2008]. 

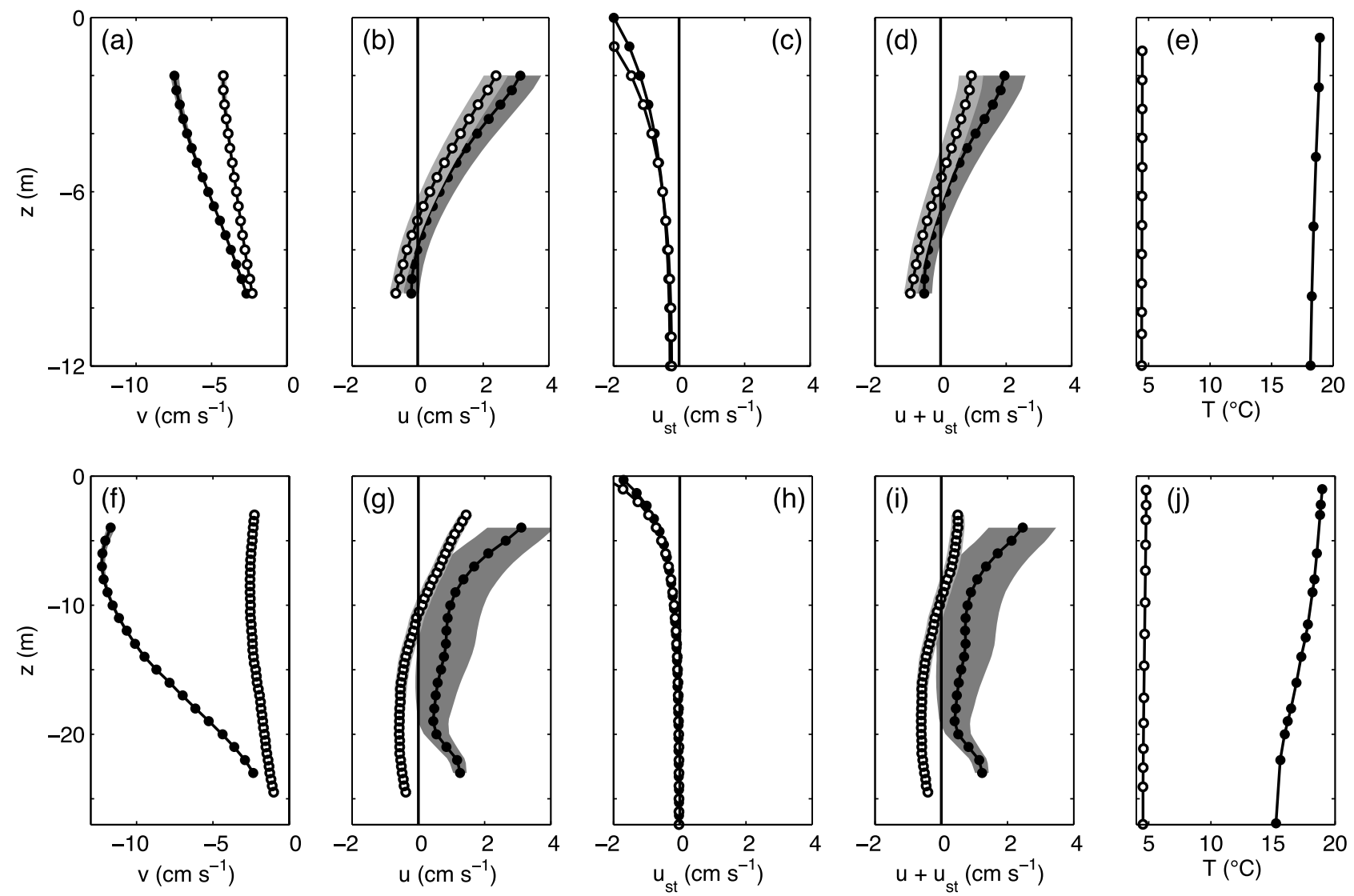

Figure 8. (a-e) The $12 \mathrm{~m}$ isobath and $(\mathrm{f}-\mathrm{j}) 27 \mathrm{~m}$ isobath. Left to right are time-mean profiles of alongshelf velocity $v$, cross-shelf velocities $u, u_{s t}, u+u_{s t}$, and temperature $T$ during the deployments in 2003 (solid symbols) and 2004-2005 (open symbols), over all times when velocity, wave, and temperature data were concurrently available. Shaded areas show range produced by rotating the coordinate system $\pm 5^{\circ}$ (too small to be visible for $v$ ).

The mean cross-shelf wind stress was weakly onshore $\left(\tau_{s}^{x}=\right.$ $-0.02 \mathrm{~Pa}$ ), opposite from the direction that would cause the observed mean circulation unless the response to fluctuating cross-shelf wind forcing is not symmetric in the direction of the wind stress. Such an asymmetry does exist in a numerical model of the stratified MAB shelf response to along-shelf wind stress [Austin and Lentz, 2002], but the stratification at the $12 \mathrm{~m}$ site is weak compared to that model. The mean upwelling circulation at the $12 \mathrm{~m}$ site is likely driven by a combination of surface gravity waves [Lentz et al., 2008], tidal rectification [Fewings et al., 2008], and an along-shelf pressure gradient [Lentz, 2008a].

[23] The inclusion of Stokes drift [Stokes, 1847], which was neglected in most prior studies, reduced the estimated cooling cross-shelf HFD by $\sim 15 \%(30 \%)$ at the $12(27) \mathrm{m}$ site (see Fewings [2007] for details). Stokes drift warms the shallow shelf in summer because the surface water is warmer than the lower water column and $u_{s t}$ is more onshore at the surface (Figure 8), so warm surface water is preferentially transported onshore: the product $u_{s t} \widetilde{T}$ in equation (4) produces warming.

[24] The tide appears to contribute only $\frac{1}{3}$ to $\frac{1}{2}$ of the highfrequency part of the cross-shelf HFD (see Fewings [2007] for details). The tidal contribution to $H^{x s}$ estimated by $\mathrm{T}_{-}$TIDE may be an underestimate if substantial baroclinic tidal motions are present but not exactly in phase with the barotropic tides.

[25] The available time series of stratification is too short to identify separately the effects of cross-shelf wind, alongshelf wind, and surface gravity waves on the part of the cross-shelf heat flux that is due to the fluctuating circulation $u$. Identifying the forcing mechanisms that are most efficient at driving cross-shelf heat flux will require a longer time series of stratification.

\section{Discussion}

\subsection{Mechanism for Achieving Steady State Balance} of Surface and Cross-Shelf Heat Fluxes

\subsubsection{Conceptual Model Without Vertical Mixing}

[26] The cross-shelf heat flux adjusts to nearly cancel the surface heat flux in summer (section 4.3). The adjustment could happen through changes in temperature stratification or cross-shelf circulation. From August to October, the surfaceto-bottom temperature difference does decrease from $\sim 2^{\circ} \mathrm{C}$ to zero at the $12 \mathrm{~m}$ site (not shown), but the cross-shelf circulation is nearly constant (Figure 9). The adjustment of the cross-shelf HFD must take place through changes in temperature stratification. 


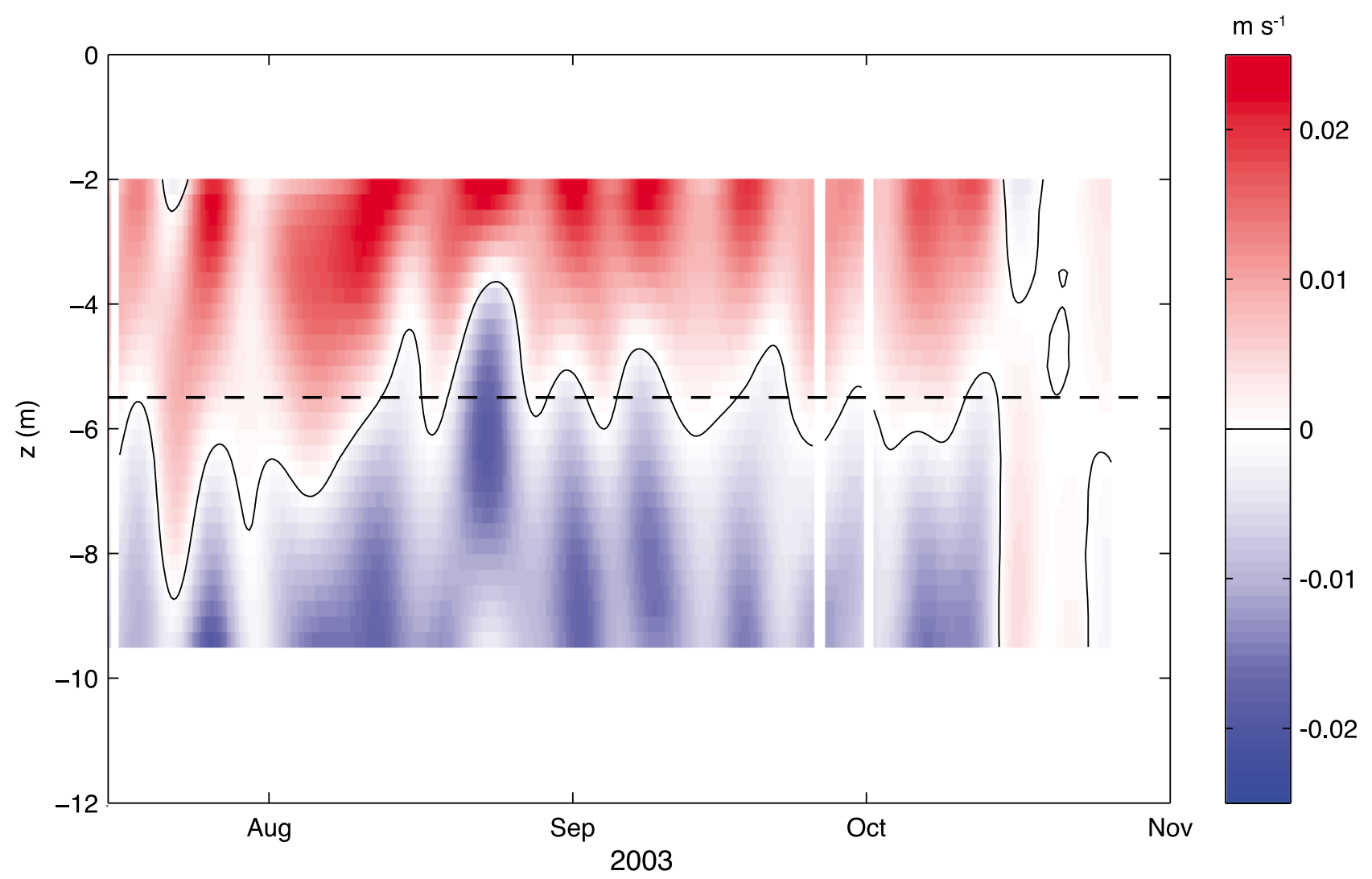

Figure 9. The 7 day low-pass-filtered cross-shelf velocity $\widetilde{u}+\widetilde{u}_{s t}$ at the $12 \mathrm{~m}$ isobath during summer 2003, with persistent offshore flow (red) in the upper layer and onshore flow (blue) in the lower layer. Dashed line indicates the layer interface at $z=-5.5 \mathrm{~m}$ used for comparison with the two-layer model.

[27] To understand how temperature stratification enables a feedback between surface and cross-shelf heat fluxes, consider a water parcel as it moves onshore in the lower water column, upwells, and warms as it travels offshore (Figure 10). The amount of warming is determined by the surface heat flux and the travel time $t$ of the parcel: $\Delta T \propto Q_{s} t$. Because the circulation is steady, the travel time is constant so $Q_{s}$ alone controls the amount of warming, which sets the vertical stratification. Stronger surface heat flux leads to stronger temperature stratification, which leads to stronger cross-shelf heat flux.

[28] The conceptual model predicts warmer water offshore because the water parcels are heated as they move offshore, but the observed temperature is colder offshore in summer [Fewings, 2007]. This suggests vertical mixing is necessary to explain the observations.

\subsubsection{Two-Layer Model With Vertical Mixing}

[29] We consider a two-dimensional two-layer model and specify a balance between surface heat flux and cross-shelf heat flux; $H^{a s}$ is small and the water temperature is constant in time. It is reasonable to use a steady state model for time scales longer than the flushing time for the shallow shelf, about 1-2 days [Fewings et al., 2008]. The model has a flat bottom at depth $z=-h$, a coastline at $x=0$, a mooring at $x=L$, a rigid lid, and an interface between the two layers at fixed depth $z=-d$ (Figure 11). The cross-shelf circulation is constant in $x$ and $z$ within each layer, except for a thin region near the coast $(0<x<\epsilon$ where $\epsilon \ll L)$ where the cross-shelf velocity goes to zero and upwelling occurs. The circulation is uniform in the along-shelf direction, consistent with observations at the $12 \mathrm{~m}$ site by Lentz et al. [2008]. Due to the short flushing time, the details of the simplified

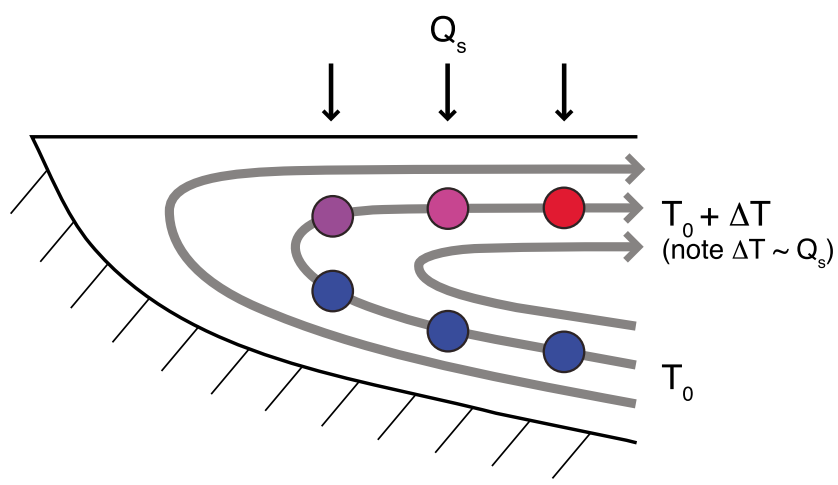

Figure 10. Schematic of the feedback between surface and cross-shelf heat fluxes. Grey streamlines qualitatively show a steady upwelling circulation during summer, neglecting vertical mixing. A water parcel with temperature $T_{0}$ (blue) upwells and warms to temperature $T_{0}+\Delta T$ (red). The surface heat flux determines $\Delta T$, and $\Delta T$ determines the crossshelf heat flux divergence. 


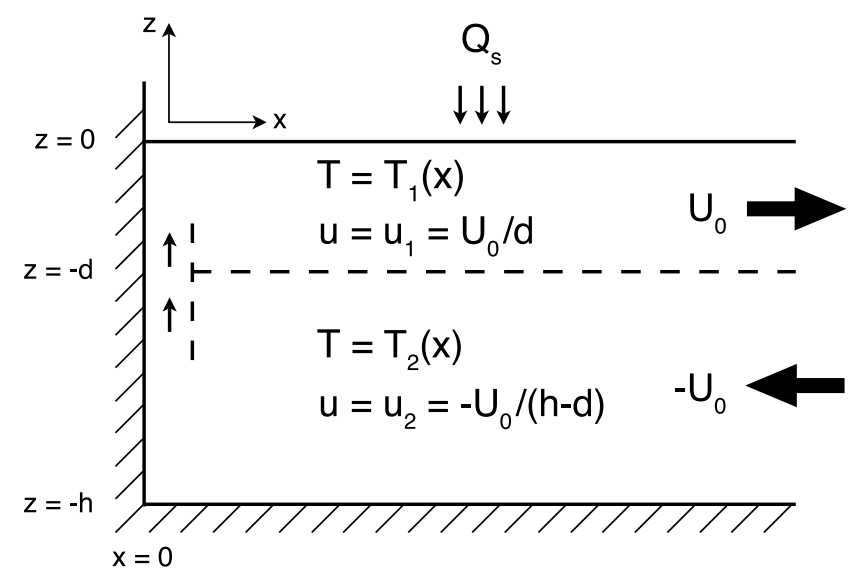

Figure 11. Cartoon of two-dimensional, two-layer model described in section 5.1.2. The cross-shelf velocity is constant in $x$ except very near the coast, where upwelling occurs. The temperature varies with $x$ in each layer.

bathymetry and circulation in the model (flat bottom and narrow upwelling region) should not qualitatively affect the results. The resulting temperature balance equation is

$$
\frac{\partial(u T)}{\partial x}+\frac{\partial(w T)}{\partial z}=\frac{\partial}{\partial z} K_{T} \frac{\partial T}{\partial z}
$$

where $K_{T}$ is the turbulent diffusivity of heat.

[30] With a coastal boundary condition of no net crossshelf flow, the two layers have equal and opposite volume transports per unit along-shelf distance of magnitude $U_{0}$ (Figure 11). The water temperature is constant in $z$ within each layer $\left(T=T_{1}\right.$ in the upper layer, and $T=T_{2}$ in the lower layer) but varies in $x$. We assume a spatially uniform surface heat flux $Q_{s}$ and no heat flux through the bottom, and define a constant entrainment velocity $w_{e}$ across the layer interface to represent mixing:

$$
\left.K_{T} \frac{\partial T}{\partial z}\right|_{z=-d}=w_{e}\left(T_{1}-T_{2}\right)
$$

For more details of the derivation, and discussion of the boundary conditions (e.g., neglect of penetrating radiation), see Fewings [2007]. To find the vertical temperature stratification $\Delta T \equiv T_{1}-T_{2}$, we integrate equation (7) vertically over each layer for $x>\epsilon$ and add the results, then set the temperature stratification $\Delta T \equiv T_{1}-T_{2}$ to zero at $x=\epsilon \approx 0$ and integrate in the cross-shelf direction:

$$
\Delta T=\frac{Q_{s}}{\rho_{0} c_{p}} \frac{x}{U_{0}}
$$

The vertical temperature stratification is independent of the strength of mixing, consistent with the conceptual model in section 5.1.1. In steady state, the net heat flux into the volume onshore of any location $x$ must be zero. Therefore $\Delta T$ adjusts, as described in the conceptual model, so the total cross-shelf advective heat flux $\rho_{0} c_{p} U_{0} \Delta T / x$ balances the surface heat flux $Q_{s}$ at every location $x$, independent of the entrainment velocity. The steady state $\Delta T$ is determined by the surface heat flux and the cross-shelf circulation alone. Only the depth-average temperature $\langle T\rangle$ depends on the entrainment velocity, as follows.

[31] To find the cross-shelf structure of the depth-average temperature $\langle T\rangle$, we combine the vertical integrals of equation (7) over the two layers to get

$$
\frac{\partial\langle T\rangle}{\partial x}=\frac{Q_{s}}{\rho_{0} c_{p}} \frac{1}{U_{0}}\left(\frac{d}{h}-\frac{w_{e}}{U_{0}} x\right)
$$

The sign of the cross-shelf temperature gradient is determined by the strength of vertical mixing: the water is warmer near shore, as observed, when mixing exchanges water between the upper and lower layers quickly enough. The model predicts the water will be warmer at the $12 \mathrm{~m}$ site than at the $27 \mathrm{~m}$ site $(\partial\langle T\rangle / \partial x<0)$ when the entrainment velocity exceeds a critical value: $w_{e}>U_{0} d / L h$ at $x=L$.

[32] For comparison with observations, we equate the entrainment velocity to an effective "bulk diffusivity": $w_{e}=$ $K_{T}^{*} / h$, so that $K_{T} \partial T / \partial z=K_{T}^{*}\left(T_{1}-T_{2}\right) / h$. Based on the observed $U_{0}=0.06 \mathrm{~m}^{2} \mathrm{~s}^{-1}$ (from the depth-varying part of $u+u_{s t}$ at the $12 \mathrm{~m}$ site during the 2003 deployment, using $u+u_{s t}$ instead of $u$ based on the form of $H^{x s}$ in equation (4)) with $d=5.5 \mathrm{~m}$ and $L=1.5 \mathrm{~km}$, the model suggests the effective mixing in summer is $K_{T}^{*}>2 \times 10^{-4} \mathrm{~m}^{2} \mathrm{~s}^{-1}$. This is consistent with observations: the $K$ profile parameterization [Large et al., 1994] indicates that $K_{T}$ is often as large as $O\left(10^{-2}-10^{-1}\right) \mathrm{m}^{2} \mathrm{~s}^{-1}$ at $2 \mathrm{~m}$ depth for the observed surface heat flux and wind stress during August 2003. Therefore, the observations at the $12 \mathrm{~m}$ site are consistent with the mechanism for balancing $H^{s}$ and $H^{x s}$ in summer that is captured by the two-layer model: an upwelling circulation that is nearly constant in time, a temperature stratification that adjusts depending on the surface heat flux, and large enough vertical mixing to yield warmer water at the $12 \mathrm{~m}$ site than the $27 \mathrm{~m}$ site.

\subsection{Stokes Drift Warms the Shallow Shelf in Summer}

[33] The contribution of wave-driven fluctuations in velocity and temperature to the heat budget through Stokes drift is substantial, $15-30 \%$ of the cross-shelf heat flux in summer, and has not been included in previous studies, with the recent exception of Lentz et al. [2010]. The entirely separate contribution of waves to the heat budget due to the wave-driven Eulerian circulation documented by Lentz et al. [2008] has automatically been included in previous studies as part of the observed circulation $u$, but was not recognized as being due to waves. Because (1) the wave-driven circulation in $u$ tends to oppose the Stokes drift $u_{s t}$ and (2) $u$ and $u_{s t}$ both act on the same temperature profile to produce a cross-shelf heat flux, there is a tendency for heat flux associated with Stokes drift to cancel heat flux associated with the wave-driven part of the Eulerian circulation $u$. The net effect of waves on the heat budget may actually be small. The cross-shelf heat flux was likely overestimated in previous studies because the canceling effect of Stokes drift was neglected.

\subsection{Comparison With Earlier Studies}

[34] The substantial cooling of the shallow shelf during summer observed here is similar to coastal upwelling on the 
West Coast of the United States in that the dominant terms in the heat balance on time scales of months are surface and cross-shelf heat flux [e.g., Lentz, 1987]. Nevertheless, there are important differences between the persistent upwelling observed at the MVCO $12 \mathrm{~m}$ site and the upwelling on the West Coast. First, the mean along-shelf wind stress at MVCO is weak in comparison to the along-shelf wind stress on the West Coast. Second, the fluctuating cross-shelf circulation over the shallow shelf near MVCO is not driven by the along-shelf wind stress as on the West Coast, but by the cross-shelf wind stress and tides [Fewings et al., 2008] and surface gravity wave forcing [Lentz et al., 2008]. The details of the stratified cross-shelf circulation over the shallow shelf in the MVCO area are not well understood.

[35] Previous observations of advective heat transport over the North Carolina continental shelf, onshore of the $23 \mathrm{~m}$ isobath, demonstrated that neither the cross-shelf nor the along-shelf HFD was a dominant term in the mean heat balance in August or October [Austin and Lentz, 1999]. In contrast, at MVCO the cross-shelf HFD is a strong cooling influence on time scales of months in summer. The North Carolina August data covered less than one month, however, so the actual mean cross-shelf HFD may have been masked by the strong synoptic variability.

[36] Our results agree with several aspects of a numerical modeling study of the summertime 2002 heat budget near MVCO [Wilkin, 2006]. In the Wilkin model, the water temperature at the 12 and $27 \mathrm{~m}$ sites also (1) increased throughout July but not as fast as the surface heat flux would suggest and (2) became constant or decreasing in August. The modeled surface heat flux was largely canceled by an advective HFD near the coast [Wilkin, 2006, Figures 10 and 11], consistent with the cooling cross-shelf HFD we observe. The advective HFD in the Wilkin model was partly due to the mean (tidally averaged) circulation, in agreement with our observations. Near the $27 \mathrm{~m}$ site (also deployed in summer 2002), the model indicated less cooling due to advective HFD than near the $12 \mathrm{~m}$ site, in agreement with the smaller discrepancy between accumulated temperature change and surface heating we observe at the $27 \mathrm{~m}$ than the $12 \mathrm{~m}$ site. The observations presented here and Wilkin's model both show that advective HFD is an important cooling mechanism in the MVCO area in summer.

[37] We document a weak warming of the shallow shelf during winter by the cross-shelf heat flux in $12 \mathrm{~m}$ water depth due to the combination of an upwelling circulation with a temperature profile that has the coldest water near the surface. This temperature profile is common in winter in the shallow MAB [Bigelow, 1933] because freshwater runoff trapped near the coast during winter can stabilize an inverted temperature profile caused by surface cooling. The inverted temperature stratification in winter 2004-2005 was a feature of only the shallowest part of the shallow shelf (the temperature was inverted at the $12 \mathrm{~m}$ but not the $27 \mathrm{~m}$ site).

\section{Summary and Conclusions}

[38] In summer, the cross-shelf heat flux is an important cooling mechanism for the shallow shelf on time scales of months. The local water temperature is nearly constant in spite of strong surface heating, due to an offshore flux of heat caused $50-60 \%$ by a mean upwelling circulation acting on the mean temperature profile (Figure 7a). At the $12 \mathrm{~m}$ site, because the mean wind is weak, that mean upwelling circulation is likely not wind driven; it is partly a tidal residual circulation, and surface gravity waves and an along-shelf pressure gradient may also contribute. The effect of Stokes drift on the cross-shelf heat flux is substantial: it cancels 15$30 \%$ of the offshore heat flux carried by the mean Eulerian circulation, a cancellation ignored in most previous studies. The cross-shelf heat flux alone provides a mechanism for the departure of the heat balance from one-dimensional (Figure 2). Though the net along-shelf heat flux divergence cannot be estimated from these observations, an along-shelf heat flux divergence comparable in size to the cross-shelf heat flux divergence is not required to close the budget, suggesting the along-shelf heat flux divergence is small. This is in contrast to previously observed midshelf sites in the MAB where the cross-shelf heat flux is less important. These results suggest the need to resolve tidal residual circulations and wave forcing in observational and numerical studies of the shallow shelf circulation and heat budget.

[39] In winter, the heat balance of the shallow shelf is closer to one-dimensional, with surface cooling and change in local heat content balancing (Figure 7b). The cross-shelf circulation is not weak in winter, but the cross-shelf heat flux becomes small because the vertical stratification is weak. The temperature difference between the near-surface and nearbottom water is always small compared to the temperature change from summer to winter (Figure 1). It is that relatively small vertical temperature stratification, however, that enables the large cross-shelf advective heat flux out of the shallow shelf in summer and keeps the water cool compared to what would be expected based on surface heating alone (Figure 2).

[40] Simple conceptual and two-layer analytical models suggest the summertime heat balance is in a slowly evolving near steady state. The steady state is maintained by a feedback between the surface and cross-shelf heat fluxes. The feedback is via changes in the temperature stratification, not the circulation; the observed upwelling circulation is nearly constant. Stronger surface heating leads to stronger temperature stratification, which leads to stronger offshore heat flux. Vertical mixing is necessary to explain the presence of warmer water near shore. Due to the short flushing time of the shallow region of any shelf $(O$ (days) for cross-shelf velocities $\left.O\left(1 \mathrm{~cm} \mathrm{~s}^{-1}\right)\right)$ the details of bathymetry and crossshelf velocity structure are not important. A similar feedback likely controls summer water temperatures in many coastal locations with broad, gently sloping continental shelves.

\section{Appendix A: Calculation of Along-Shelf Advective Heat Flux Divergence}

[41] We estimated $H_{a d v}^{a s}$, the first term in equation (6), onshore of the $12 \mathrm{~m}$ site by using moorings $\mathrm{T} 1$ and T2 to represent the along-shelf temperature gradient. Those moorings were deployed in 2003 on approximately the $15 \mathrm{~m}$ isobath (Figure 3). If we assume the along-shelf velocity as a function of $\sigma \equiv z / h$ decreases linearly from its value at the $12 \mathrm{~m}$ site to $v=0$ at the coast, $x=0$, then

$$
v(x, \sigma, t)=v(L, \sigma, t) \frac{x}{L}
$$


and if we assume the along-shelf temperature gradient (as a function of $\sigma$ ) is constant in $x$, then

$$
\frac{\partial T}{\partial y}(x, \sigma, t)=\frac{\partial T}{\partial y}\left(\left.x\right|_{h=15 \mathrm{~m}}, \sigma, t\right)
$$

Because $\left.\langle T\rangle\right|_{x=L}$ is a function only of $t$, by changing coordinates from $z$ to $\sigma$ in the vertical integral we find

$$
H_{a d v}^{a s}=-\rho_{0} c_{p} \int_{0}^{L} \frac{x}{L} h(x) d x \int_{-1}^{0} v(L, \sigma, t) \frac{\partial T}{\partial y}\left(\left.x\right|_{h=15 \mathrm{~m}}, \sigma, t\right) d \sigma
$$

We estimated the vertical integral by interpolating $v$ and $T$ onto a common $\sigma$ grid and using a first difference approximation to $\partial T / \partial y$ and a trapezoidal approximation for the integral, assuming constant $v$ and $T$ values from the top (bottom) measurement to $\sigma=0(\sigma=-1)$.

[42] Acknowledgments. We thank Glenn Flierl, Robert Beardsley, Glen Gawarkiewicz, Heidi Sosik, Carlos Moffat-Varas, J. Tom Farrar, and anonymous reviewers for helpful suggestions about the manuscript; Robert Weller and John Trowbridge for mooring data from the 2003 deployment (CBLAST); Robert Beardsley and Carlos Moffat for the MATLAB heat flux algorithm; Greg Gerbi for help with the $K$ profile parameterization; Janet Fredericks and Craig Marquette for data downloading; and J. Tom Farrar, Jim Lerczak, Jay Sisson, Craig Marquette, Jim Dunn, Jeff Lord, Scott Worrilow, John Lund, Rick Rupan, Carlos Moffat-Varas, Jessica Warren, Clare Williams, Greg Gerbi, the captain and crew of the R/V Connecticut, and Captain Ken Houtler and crew member Ian Hanley of R/V Tioga, for construction, deployment, and recovery of moorings. This research was funded by National Aeronautics and Space Administration Headquarters grant NNG04GL03G and Earth System Science Fellowship Grant NNG04GQ14H; Woods Hole Oceanographic Institution through Academic Programs Fellowship Funds and MVCO; National Science Foundation grants OCE-0241292, OCE-0548961, and OCE-0337892; the Jewett/ EDUC/Harrison Foundation; and Office of Naval Research contracts N00014-01-1-0029 and N00014-05-10090 for the Low-Wind Component of the Coupled Boundary Layers Air-Sea Transfer Experiment.

\section{References}

Austin, J. A. (1999), The role of the alongshore wind stress in the heat budget of the North Carolina inner shelf, J. Geophys. Res., 104(C8), $18,187-18,204$

Austin, J. A., and S. J. Lentz (1999), The relationship between synoptic weather systems and meteorological forcing on the North Carolina inner shelf, J. Geophys. Res., 104(C8), 18,159-18,185.

Austin, J. A., and S. J. Lentz (2002), The inner shelf response to winddriven upwelling and downwelling, J. Phys. Oceanogr., 32, 2171-2193.

Berger, T. J., J. O. Blanton, W. C. Boicourt, J. H. Churchill, P. Hamilton, R. J. Wayland, and D. R. Watts (1994), A physical oceanographic field program offshore of North Carolina: Final synthesis report, Rep. MMS 94-0047, 463 pp., Miner. Manage. Serv., U.S. Dep. of the Inter., New Orleans, La.

Bigelow, H. B. (1933), Studies of the waters on the continental shelf, Cape Cod to Chesapeake Bay. I. The cycle of temperature, Pap. Phys. Oceanogr. Meteorol., 2(4), 1-135.

Bignami, F., and T. S. Hopkins (2003), Salt and heat trends in the shelf waters of the southern Middle-Atlantic Bight, Cont. Shelf Res., 23(6), 647-667.

Dever, E. P., and S. J. Lentz (1994), Heat and salt balances over the Northern California shelf in winter and spring, J. Geophys. Res., 99(C8), $16,001-16,017$.
Fairall, C. W., E. F. Bradley, J. E. Hare, A. A. Grachev, and J. B. Edson (2003), Bulk parameterization of air-sea fluxes: Updates and verification for the COARE algorithm, J. Clim., 16, 571-591.

Fewings, M. R. (2007), Cross-shelf circulation and momentum and heat balances over the inner continental shelf near Martha's Vineyard, Massachusetts, Ph.D. thesis, 267 pp., MIT/WHOI Joint Program in Oceanography/ Applied Ocean Science and Engineering, Woods Hole, Mass. (Available at http://hdl.handle.net/1912/2121)

Fewings, M. R., S. J. Lentz, and J. Fredericks (2008), Observations of cross-shelf flow driven by cross-shelf winds over the inner continental shelf, J. Phys. Oceanogr., 38(11), 2358-2378.

Flagg, C. N., L. J. Pietrafesa, and G. L. Weatherly (2002), Springtime hydrography of the southern Middle Atlantic Bight and the onset of seasonal stratification, Deep Sea Res., Part II, 49(20), 4297-4329.

Hickey, B. (1979), The California current system-Hypotheses and facts, Prog. Oceanogr., 8(4), 191-279.

Jerlov, N. G. (1968), Optical Oceanography, Oceanogr. Ser., vol. 5, Elsevier, New York.

Joyce, T. M. (1987), Meteorology and air-sea interactions, in The Marine Environment of the U.S. Atlantic Continental Slope and Rise, edited by J. D. Milliman and W. R. Wright, pp. 5-26, Jones and Bartlett, Boston, Mass.

Kohut, J. T., S. M. Glenn, and R. J. Chant (2004), Seasonal current variability on the New Jersey inner shelf, J. Geophys. Res., 109, C07S07, doi:10.1029/2003JC001963.

Large, W. G., J. C. McWilliams, and S. C. Doney (1994), Oceanic vertical mixing: A review and a model with a nonlocal boundary layer parameterization, Rev. Geophys., 32(4), 363-404.

Lentz, S. J. (1987), A heat budget for the northern California shelf during CODE 2, J. Geophys. Res., 92(C13), 14,491-14,509.

Lentz, S. J. (2008a), Observations and a model of the mean circulation over the Middle Atlantic Bight continental shelf, J. Phys. Oceanogr., 38(6), 1203-1221.

Lentz, S. J. (2008b), Seasonal variations in the circulation of the Middle Atlantic Bight continental shelf, J. Phys. Oceanogr., 38(7), 1486-1500.

Lentz, S. J., R. C. Beardsley, J. D. Irish, J. Manning, and R. A. Weller (2003a), Temperature and salt balances on Georges Bank FebruaryAugust 1995, J. Geophys. Res., 108(C11), 8006, doi:10.1029/ 2001JC001220.

Lentz, S. J., K. Shearman, S. P. Anderson, A. Plueddemann, and J. Edson (2003b), Evolution of stratification over the New England shelf during the Coastal Mixing and Optics study, August 1996-June 1997, J. Geophys. Res., 108(C1), 3008, doi:10.1029/2001JC001121.

Lentz, S. J., M. R. Fewings, P. Howd, J. Fredericks, and K. Hathaway (2008), Observations and a model of undertow over the inner continental shelf, J. Phys. Oceanogr., 38(11), 2341-2357.

Lentz, S. J., R. K. Shearman, and A. J. Plueddemann (2010), Heat and salt balances over the New England continental shelf, August 1996 to June 1997, J. Geophys. Res., 115, C07017, doi:10.1029/2009JC006073.

Limeburner, R., et al. (1985) CODE-2: Moored array and large-scale data report, Tech. Rep. 85-35, Woods Hole Oceanogr. Inst., Woods Hole, Mass.

Paulson, C. A., and J. J. Simpson (1977), Irradiance measurements in the upper ocean, J. Phys. Oceanogr., 7(6), 952-956.

Pawlowicz, R., R. C. Beardsley, and S. J. Lentz (2002), Harmonic analysis including error estimates in MATLAB using T TIDE, Comput. Geosci., 28(8), 929-937.

Pedlosky, J. (1987), Geophysical Fluid Dynamics, 2nd ed., 710 pp., Springer, New York

Saunders, P. M. (1977), Wind stress on the ocean over the eastern continental shelf of North America, J. Phys. Oceanogr., 7(4), 555-566.

Stokes, G. G. (1847), On the theory of oscillatory waves, Trans. Cambridge Philos. Soc., 8, 441-455.

Wilkin, J. L. (2006), The summertime heat budget and circulation of southeast New England shelf waters, J. Phys. Oceanogr., 36(11), 1997-2011.

M. R. Fewings, Marine Science Institute, University of California, Santa Barbara, CA 93106-6150, USA. (fewings@msi.ucsb.edu)

S. J. Lentz, Department of Physical Oceanography, Woods Hole Oceanographic Institution, MS 21, Woods Hole, MA 02543, USA. (slentz@whoi.edu) 